\title{
A survey of contemporary usage of epicardial pacing wires among UK cardiothoracic surgeons: A call for a more conservative approach
}

\author{
Vivek Srivastava*, Pankaj Kumar Mishra, Enoch Akowuah, Joel Dunning, Jonathan Ferguson, Andrew Goodwin, \\ Simon Kendall, Andrew Owens, Ralph White
}

From World Society of Cardiothoracic Surgeons 25th Anniversary Congress, Edinburgh Edinburgh, UK. 19-22 September 2015

\section{Background/Introduction}

To determine current practice regarding the use of epicardial pacing wires by cardiothoracic surgeons in the U.K.

\section{Aims/Objectives}

To determine current practice regarding the use of epicardial pacing wires by cardiothoracic surgeons in the U.K.

\section{Method}

An internet-based survey was distributed via email to all U.K. cardiac and cardiothoracic surgeons. The questionnaire consisted of 18 questions regarding use and management of epicardial pacing wires.

\section{Results}

Of 282 questionnaires, 126 responses were received (response rate 44.7\%). Around two thirds (68.3\%) of respondents routinely used epicardial wires for isolated coronary artery bypass grafts (CABG). Both atrial and ventricular wires were favoured for valve cases: isolated aortic valve( $60.3 \%$ respondents), isolated mitral valve (63.5\%), multiple valves(70\%), CABG \& valve(63.5\%), redo valve(67.5\%). The main reasons quoted for not using pacing wires: perception as an unnecessary procedure(22.2\%), risk of bleeding $(25.4 \%)$ and potential for delayed discharge(17.5\%). Around half (54\%) of surgeons reported practising minimally invasive techniques and $36.8 \%$ of these modified pacing wire usage. Two-thirds of surgeons accepted an INR of $<2.5$ for removal of pacing wires with another $24.6 \%$ accepting an INR $<3.0$ ( $>91 \%$ overall). Seventy percent would not remove pacing wires outside daytime hours although 54\% removed them over weekends and holidays. Postoperative day 3 or 4 was the most common day for removal. Forty-five percent of respondent surgeons were comfortable discharging patients the day the wires were removed.

\section{Discussion/Conclusion}

Results show considerable variation in practice. Modifications based on peer practice could potentially save bed-days (by increasing pacing wire removal over weekends and out-of-hours and same-day discharge), reduce costs (clarifying indications and reducing routine use) and reduce risk of bleeding (by standardising safe level of anticoagulation).

Published: 16 December 2015

doi:10.1186/1749-8090-10-S1-A342

Cite this article as: Srivastava et al.: A survey of contemporary usage of epicardial pacing wires among UK cardiothoracic surgeons: A call for a more conservative approach. Journal of Cardiothoracic Surgery 201510 (Suppl 1):A342. 